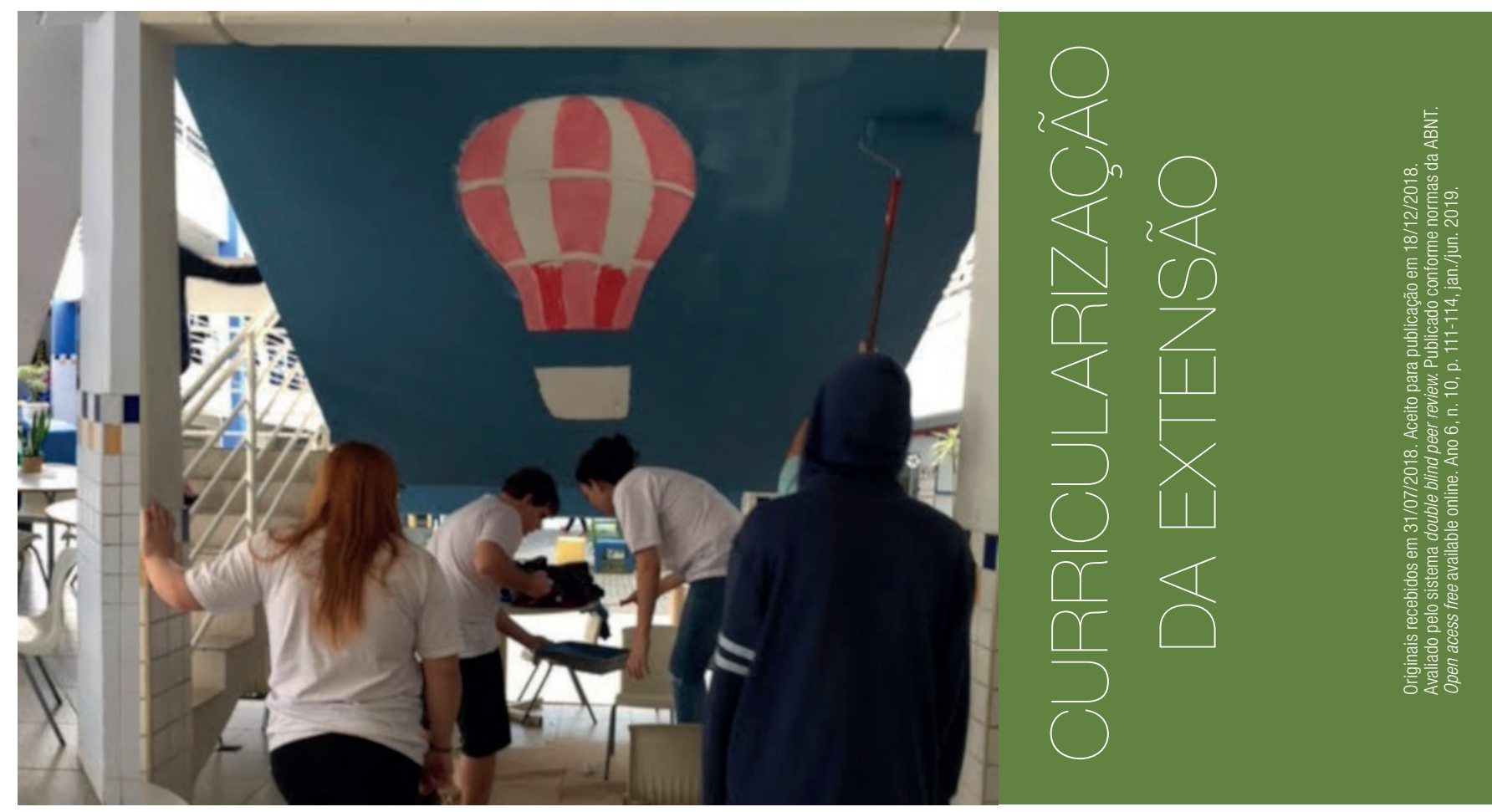

\title{
Curricularização da Extensão no Câmpus Itajaí do Instituto Federal de Santa Catarina (IFSC) - conquistas e desafios
}

Fernanda I. M. Argoud da Silva - fargoud@ifsc.edu.br ${ }^{1}$

Rafaela Garcia - garciarafaelam@gmail.com²

\section{RESUMO}

0 projeto pedagógico do curso de Engenharia Elétrica do Câmpus Itajaí do IFSC foi concebido em 2014, com a preocupação de se fazer a curricularização da Extensão e inclusão das atividades complementares daquele curso, e com foco na importância do tripé ensino-pesquisaextensão. Desde então, o curso avançou consideravelmente em se apropriar dessa metodologia educacional e em implantar a Extensão no currículo de forma orgânica, com o apoio institucional da Rede. Porém, muito ainda precisa ser feito no sentido de que se possa ofertar regularmente propostas de atividade de Extensão e de atividades complementares, como mais uma rotina no curso de graduação, minimizando o trabalho extra para o docente coordenador, proponente de projetos de Extensão. 0 presente relato descreve conquistas e desafios do projeto Intervenção e sugere caminhos pelos quais o IFSC poderia dinamizar a curricularização da Extensão.

\footnotetext{
1 Engenheira Eletricista (1993); mestre em Engenharia (1996); doutora em Engenharia (2001) e docente do IFSC desde dezembro de 2005.

2 Acadêmica do curso de Engenharia Elétrica do IFSC- Câmpus Itajaí e bolsista do projeto Intervenção.
} 


\section{PALAVRAS-CHAVE}

Extensão. Curricularização. Atividades Complementares. Engenharias.

\section{ABSTRACT}

Since the beginning, at 2014, the course of Electrical Engineering of Campus Itajai was conceived in a perspective of integrating Extension, and Complementary Activities, in an organic manner, in the curriculum. Beside the advances in understanding this process, much more have to be done in therms of aidding the coordinators to manage and propose projects. This article reports the Intervenção Project, its issues and advances, and suggests some manners to progress and foment the process.

\section{KEYWORDS}

Extension. Curriculum. Complementary Activities. Engineerings.

\section{Relato de caso}

Em junho de 2014, um grupo de cinco professores reuniu-se para discutir a oferta de um curso de Engenharia Elétrica no Câmpus Itajaí, já com a preocupação de que a construção do currículo atendesse as recomendações, normativas e diretrizes da Secretaria de Ensino Tecnológico (SETEC, 2009), do Conselho Nacional de Educação (CNE), da Secretaria de Ensino Superior (Sesu, 2002) e o próprio Colegiado de Ensino, Pesquisa e Extensão do IFSC (IFSC-CEPE, 2010), com relação ao perfil do engenheiro eletricista e dos cursos de Engenharia Elétrica da rede, bem como para a curricularização da Extensão e atividades complementares obrigatórias. No Projeto Pedagógico ficou estabelecido que os alunos do curso deveriam despender uma carga horária mínima de 400 horas, ou 40 horas por semestre, em média, em atividades de extensão e complementares. Atualmente, o curso oferta cinco disciplinas de atividades complementares regulares, das quais três são de atividades de Extensão, incluindo-se nestas 0 projeto Intervenção, já em sua terceira turma.

0 projeto "INTERvenção - a extensão como ferramenta de integração e mobilização" foi pensado, exatamente, como uma forma de mobilizar alunos do Câmpus Itajaí em atividades práticas diversas, com foco no trabalho de melhorias em escolas públicas do município. Foi submetido ao Edital Proex 02/2017, como uma oferta-piloto de projeto de Extensão inserido em uma disciplina regular do curso (e, portanto, curricularizado), ao mesmo tempo que se permitia aos alunos do curso que trabalhassem nele de forma voluntária e com registro de horas de atividades complementares obrigatórias no semestre. Na ocasião, os docentes do curso entenderam que horas despendidas em projetos de extensão e em atividades de cunho social poderiam ser contabilizadas como atividades complementares, por parte dos alunos, o que depois foi regulamentado no curso, através de documento próprio (IFSC - CÂMPUS ITAJAÍ, 2016).

\section{Atividades desenvolvidas}

A primeira edição do projeto foi realizada durante seis meses de 2017, na Escola Básica Professora Maria Dutra Gomes (EBPMDG), e em um período de oito meses do ano de 2018, no Centro Educacional Pedro Rizzi (CEPR).

Em ambas as propostas, a ideia foi coordenar uma série de ações de caráter social, educativo, esportivo e técnico a serem executadas por alunos do curso superior de Engenharia Elétrica do IFSC - Câmpus Itajaí, dentro do conceito sustentável, e como parte das suas atividades obrigatórias de extensão e complementares. 
Também eram objetivos: auxiliar na aproximação do IFSC com a comunidade municipal e dessa, com o Câmpus Itajaí; promover a Extensão, a Iniciação Científica e o empreendedorismo no câmpus, e ajudar a formar consciência crítica e cidadã nos alunos, entre outros.

Inúmeras melhorias, revitalização de espaços e atividades de caráter técnico, educacional, artístico e social foram desenvolvidas nas duas escolas, tais como:

- pesquisa e desenvolvimento de um placar eletrônico microcontrolado, para a quadra de esportes da EBPMDG,

- conserto de porta automática da EBPMDG,

- instalação de alarmes manual e automático da EBPMDG,

- confecção e substituição de murais na EBPMDG,

- lavagem e pintura de muros e paredes, em ambas as escolas,

- espalhamento de brita pelos pátios, na EBPMDG,

- construção, montagem e pintura de arquibancada de pallets, para a quadra da EBPMDG,

- $\quad$ pintura de nove murais decorativos no CEPR (um deles com $30 \mathrm{~m}^{2}$, representando Itajaí e região),

- colocação de papel de parede na sala da Direção e sala de professores do CEPR,

- aplicação de questionários de avaliação, em ambas as escolas, etc.

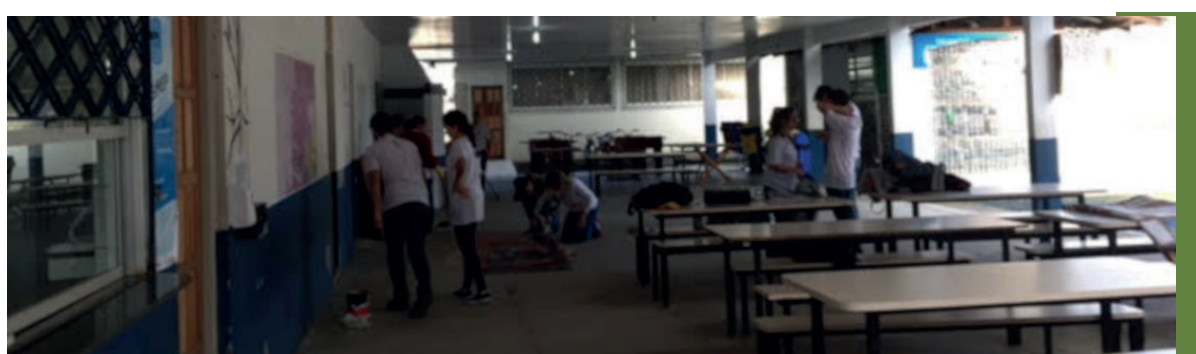

Figura 1: Alunos trabalhando na substituição dos murais da EBPMDG, maio de 2017

Fonte: Dados desta pesquisa.

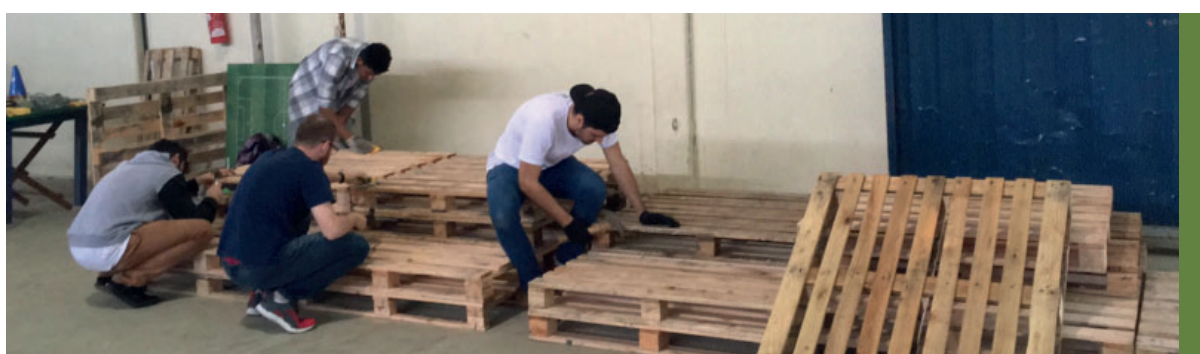

Figura 2: Alunos construindo

arquibancadas para a EBPMDG, setembro de 2017.

Fonte: Dados desta pesquisa.

Nas três edições, os alunos tiveram oportunidade de realizar pesquisas científicas acerca dos problemas apresentados; discutir as propostas no grupo e estudar a melhor forma de aplicá-las; e levar estas soluções às comunidades, no caso, todos os alunos, pais de alunos, professores e servidores que compõem as escolas atendidas.

Ao final de todos os períodos, foram aplicados questionários de avaliação e validação, como forma de alimentar e aprimorar as edições futuras do projeto.

\section{Resultados obtidos}

Em ambas as edições avaliadas, a aceitação foi além do esperado (mais de 85\% da comunidade avaliou o projeto como "Positivo" ou "Muito positivo"), indicando o atendimento dos objetivos do projeto. As comunidades das duas escolas apontaram todas as melhorias citadas no capítulo anterior como tendo beneficiado significativamente a rotina escolar. Aproximadamente $97 \%$ dos alunos, docentes e servidores afirmaram ter observado melhorias ou grandes melhorias após o 
projeto e quase $79 \%$ dos respondentes afirmaram que gostariam que o projeto retornasse às suas escolas.

0 maior desafio encontrado foi exatamente na mobilização interna. Apenas 41 dos 126 alunos matriculados no curso participaram do projeto nas três edições, o que a coordenação considerou uma baixa participação (32\%, aproximadamente). Na terceira edição, apesar de 56 alunos terem se inscrito no projeto, e se matriculado na disciplina de Extensão, apenas 30 tiveram frequência. 0 principal motivo apontado (58\%) para a baixa participação foi a "falta de tempo e disponibilidade", mas muitos alunos (34\%) também citaram a "dificuldade de locomoção até a escola". Cabe salientar que as duas escolas distam, mais ou menos, dois quilômetros do Câmpus Itajaí.

Além disso, consideraram-se como pontos negativos os prazos apertados de editais de extensão e a dificuldade para se submeter projetos a estes editais, dentro da plataforma SIGAA. Esta plataforma exige um número excessivo e redundante de documentos e autorizações, não sendo transparente nem amigável. A segunda edição do projeto, por exemplo, não pode ser submetida para obtenção de recursos em editais, porque o sistema exigiu várias autorizações de coordenações, que não são ligadas ao curso de Engenharia Elétrica e que não foram enviadas. Considera-se fundamental que esses problemas de prazos e plataforma sejam sanados, para que atividades de Extensão possam ser efetivamente integradas aos currículos das engenharias no IFSC.

Apesar das dificuldades, o projeto continuou a avançar e foi submetido ao terceiro edital (Proex 18, 2018) e aprovado, para captação de recursos para as atividades de melhorias nas escolas e bolsas para os alunos. Mais importante que isto, os alunos do curso também já compreendem as atividades e disciplinas de Extensão como parte fundamental de seus itinerários formativos.

\section{Referências}

IFSC-CEPE, 2010. COLEGIADO DE ENSINO, PESQUISA E EXTENSÃO (CEPE). Deliberação Cepe/IFSC $\mathbf{n}^{\circ}$ 044, de 06 de outubro de 2010, "Estabelece Diretrizes para os Cursos de Engenharia no IFSC". Disponível em: http://cs.ifsc.edu.br/portal/files/deliberacoes_cepe2010/ CEPE_deliberacao_044_2010.pdf. Acesso em 4 de novembro 2011.

IFSC-CAMPUS ITAJAÍ, 2014. Projeto Pedagógico Do Curso De Bacharel Em

Engenharia Elétrica. Disponível em: https://wiki.ifsc.edu.br/mediawiki/images/1/1b/PPCEEL. pdf. Acesso em 31/07/2018.

IFSC-CAMPUS ITAJAÍ, 2016. Regulamento Transitório Das Atividades Complementares Do Curso De Engenharia Elétrica Do Ifsc. Disponível em: http://wiki.itajai.ifsc.edu. br/images/5/59/Regulamento_Transit\%C3\%B3rio_de_Atividades_Complementares_ EEL_\%28v_1.4\%29\%28por_valida\%C3\%A7\%C3\%A30\%29.pdf. Acesso em 31/07/2018.

SESU, 2002. BRASIL-MEC-SECRETARIA DE EDUCAÇÃO SUPERIOR (SESU). Referenciais Nacionais para os cursos de Engenharia. Disponivel em http://portal.mec.gov.br/ dmdocuments/referenciais2.pdf. Acesso em 31/07/2018.

SETEC, 2009. BRASIL-MEC-SECRETARIA DE EDUCAÇÃO PROFISSIONAL E TECNOLÓGICA. Princípios Norteadores das Engenharias nos Institutos Federais. Disponível em: http:// mec.gov.br/ setec/arquivos/pdf/principios_norteadores.pdf. Acesso em 4 de novembro 2011. 